\title{
Clinical significance of 5-(and 6)-carboxyfluorescein diacetate succinimidyl ester-labeled microspheres for detecting endothelial progenitor cells in human peripheral blood
}

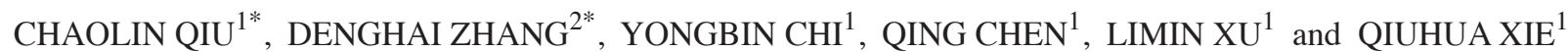 \\ ${ }^{1}$ Clinical Laboratory Department; ${ }^{2}$ Central Laboratory Department, Shanghai Gongli Hospital, \\ The Second Military Medical University, Shanghai 200135, P.R. China
}

Received January 21, 2016; Accepted February 14, 2017

DOI: $10.3892 / e t m .2017 .4657$

\begin{abstract}
The aims of the present study were to establish a single-platform flow cytometry method using 5-(and 6)-carboxyfluorescein diacetate succinimidyl ester (CFSE)-labeled microspheres as the reference for determining endothelial progenitor cell (EPC) number and to evaluate the efficacy of this detection method. Single-platform flow cytometry was used to count cell numbers using CFSE-stained fluorescent microspheres as the internal reference and the EPC numbers in specimens using this novel method were compared with an in vitro clonogenic counting assay. The results of the two counting methods were consistent and compared with the in vitro clonogenic counting assay, the time and cost of the novel method was markedly reduced, as were the corresponding technical requirements. The present findings indicated that single-platform flow cytometry, with CFSE-labeled microspheres as the reference, provides faster and improved detection of EPCs in human peripheral blood specimens, with reduced time and cost, making it more suitable for routine clinical application.
\end{abstract}

\section{Introduction}

The occurrence, development and metastasis of tumors are closely related to angiogenesis due to the fact that blood vessels provide the necessary oxygen supply, nutrition, metabolite and avenue for metastasis to maintain the rapid

Correspondence to: Dr Limin Xu or Professor Qiuhua Xie, Clinical Laboratory Department, Shanghai Gongli Hospital, The Second Military Medical University, 219 Miaopu Road, Shanghai 200135, P.R. China

E-mail: liminxuc@yeah.net

E-mail: chaolinqiu@163.com

*Contributed equally

Key words: carboxyfluorescein diacetate succinimidyl ester, single-platform flow cytometry, endothelial progenitor cells growth of tumors (1-3). Angiogenesis, which is the generation of novel blood vessels, occurs by two completely different processes (4-6). In the first, the required vascular endothelial cells arise from the sprouting of existing blood vessels. In the second, they are derived from recruited endothelial precursor cells, which are a type of blast cell with the potential to differentiate into clonal endothelial cells in vitro as well as participate in cardiovascular generation in vivo (7). On their surface, they characteristically express cluster of differentiation (CD)34, vascular endothelial growth factor receptor 2 (VEGFR2) or kinase domain receptor $(8,9)$.

A large number of basic and clinical studies have indicated that the number of endothelial progenitor cells (EPCs) is closely related to tumor size, prognosis and therapy response (10-13). Evidence from animal models suggests that the EPC level in the peripheral circulation has some relevance to tumor volume (13). The number of EPCs in circulation has been identified to alter with anti-tumor and anti-angiogenesis therapies. Igreja et al (14) suggested that the EPC level in the peripheral blood of patients with lymphoma was related to the efficacy of the therapy. This hypothesis was supported by the fact that the EPC level in patients with complete remission decreased, while EPC levels continued to rise or did not change in those with partial remission or no response to therapy. In addition, it was revealed that tumor size and angiogenesis were associated with the number of EPCs in lymph nodes. Ho et al (15) indicated that, in patients with advanced non-surgically treated hepatocellular carcinoma (HCC), the EPC level in circulation was significantly higher compared with patients with resectable HCC, suggesting that the number of EPCs in the peripheral circulation may be used to determine the prognosis of HCC patients.

Currently, EPC detection methods include clone counting and characteristic index-based flow cytometry, of which the latter may be divided into dual-platform counting and single-platform counting $(14,16,17)$. Dual-platform counting, which involves two parallel tubes and two devices, exhibits large variations in results. Conversely, single-platform counting uses commercialized fluorescent microspheres, which are expensive and easily adhere. Artificially synthesized fluorescent microspheres have a different sedimentation rate than cells, leading to unreliable results (18-20). In our previous 
study, CFSE-labeled cells were used to replace commercial fluorescent microspheres (21). We suggested that these fluorescence-labeled cells were stable and did not easily adhere; thus, the test results were reliable (21).

Due to the clinical value of EPCs, establishing an improved complete EPC counting method is crucial. The present study used single-platform flow cytometry technology with CFSE-labeled cell fluorescent microspheres as the internal control to determine the number of EPCs in peripheral blood and subsequently verify the reliability of this technology from a biological standpoint. Furthermore, this recently developed technology was used to detect the changes in EPC number following tumor anti-angiogenic therapy. Subsequently, the clinical value of using CFSE-labeled cell microspheres with single-platform flow cytometry for determining EPC number in peripheral blood was verified.

\section{Materials and methods}

Preparation and identification of artificial cell microspheres. A total of $50 \mu \mathrm{g}$ (1 vial) of CFSE (Molecular Probes; Thermo Fisher Scientific Inc., Waltham, MA, USA) was dissolved in $18 \mu \mathrm{l}$ of dimethyl sulfoxide to prepare the original solution with a final concentration of $5 \mathrm{mmol}$, which was stored at $-20^{\circ} \mathrm{C}$. Subsequently, $1 \mathrm{~g}$ of paraformaldehyde (PFA, Sigma-Aldrich; Merck KGaA, Darmstadt, Germany) was dissolved in $90 \mathrm{ml}$ of distilled water and $10 \mathrm{ml}$ of 10X phosphate-buffered saline (PBS) was added to prepare a 1\% PFA solution. The THP-1 human acute leukemia cell line (Cell Bank of Shanghai Institute, Shanghai, China) was cultured in RPMI 1640 medium supplemented with $10 \%$ fetal bovine serum (FBS; GE Heathcare Life Sciences, Chalfont, UK). THP-1 cells were washed with PBS three times and resuspended to a concentration of $1 \times 10^{6}$ cells $/ \mathrm{ml}$. Subsequently, $1 \mu \mathrm{l}$ CFSE was added for each $\mathrm{ml}$ of cell suspension (to a final concentration of $5 \mu \mathrm{mol} / \mathrm{l}$ ) followed by incubation at $37^{\circ} \mathrm{C}$ for $10 \mathrm{~min}$. The original medium was added until a volume that was five times the original volume was achieved to terminate the marking procedure. The mixture was placed in an ice bath between 0 and $8^{\circ} \mathrm{C}$ for $5 \mathrm{~min}$, followed by washing three times with fresh medium. Cells were resuspended in PBS supplemented with $1 \%$ PFA, with a cell concentration of $1 \times 10^{6}$ cells $/ \mathrm{ml}$ and stored at $4^{\circ} \mathrm{C}$ until subsequent use. Non-marked THP-1 cells were used as a control. The prepared cell mixture, with artificial cell microspheres, was subsequently evaluated using flow cytometry.

Single-platform flow cytometry for determining the number of EPCs in peripheral blood. A total of $10 \mathrm{ml}$ of human peripheral blood (anticoagulated with $1.8 \mathrm{mg} / \mathrm{ml}$ EDTA-K2) obtained from healthy volunteers was harvested for the extraction of mononuclear cells and the sample was divided into four parts, with respective volumes of 5, 2.5, 1.25 and $0.625 \mathrm{ml}$. Samples underwent negative selection, in which CD45 antibody-coated magnetic beads (Dynabeads; Thermo Fisher Scientific, Inc.) were added and the mixture was subjected to a magnetic field to adsorb cells that were able to bind the CD45 antibody-coated magnetic beads, thus removing non-EPC components. CD34, CD133 and KDR, commonly used membrane markers to define EPCs, were detected in cells by flow cytometry as described previously (4). Subsequently, the target cells were pre-treated with an Fc-receptor-blocking reagent (Miltenyi Biotec $\mathrm{GmbH}$, Bergisch-Gladbach, Germany) to prevent non-specific binding and were incubated with an APC-conjugated-CD34 antibody (cat. no. 340441; 1:167; BD Biosciences, San Jose, CA, USA), a phycoerythrin-conjugated anti-KDR antibody (cat. no. FAB357p; 1:100; R\&D Systems, Inc., Minneapolis, MN, USA) and a phycoerythrin-conjugated anti-CD133 antibody (cat. no. 130-080-801; 1:100; Miltenyi Biotec $\mathrm{GmbH}$ ) at $4^{\circ} \mathrm{C}$ for $40 \mathrm{~min}$. A total of 10,000 CFSE-labeled microspheres were added to the test sample and washed with PBS three times. The sample was thoroughly mixed before counting. Red blood cells were lysed with ammonium chloride (BD Biosciences, San Jose, CA, USA) and a total of $10^{6}$ events were recorded on a FACS Calibur cytometer (BD Biosciences). Data were analyzed with CellQuest software (version 5.2.1; BD Biosciences).

The absolute number of cells inside the test sample (ND) was calculated using the following formula: Absolute number of cells=target cell number/number of cell microspheres $x$ added number of cell microspheres.

Identifying EPCs and determining the number of EPCs in peripheral blood. A total of $10 \mathrm{ml}$ of human peripheral blood was collected and divided into four parts, with volumes of 5 , $2.5,1.25$ or $0.625 \mathrm{ml}$. A single karyoplast was obtained by the density centrifugation method and planted onto a human fibronectin-coated culture plate and cultured in M199 medium (Invitrogen; Thermo Fisher Scientific, Inc.) supplemented with $20 \%$ FBS, $10 \mathrm{ng} / \mathrm{ml}$ VEGF, $100 \mathrm{ng} / \mathrm{ml}$ penicillin and $100 \mathrm{ng} / \mathrm{ml}$ streptomycin for 2 days. Following culturing for 2 days, the mature endothelial cells had adhered to the wall and the non-wall-adherent cells were collected and re-planted onto human fibronectin-coated culture plates for final counting. The medium was changed once every 3 days and the non-wall-adherent cells were washed off with PBS 7 days later. Subsequently, $2.4 \mathrm{mg} / 1$ of 1,1'-dioctadecy1-3,3,3'3'-tetramethyl-indocarbocyanin perchlorate-labeled-acetylated-low density lipoprotein (Thermo Fisher Scientific, Inc.) was added to the cultured cells, followed by incubation at $37^{\circ} \mathrm{C}$ in an atmosphere containing $5 \% \mathrm{CO}_{2}$ for $12 \mathrm{~h}$. Cells were fixed with $2 \%$ PFA for $30 \mathrm{~min}$, followed by washing with D-Hank's solution (GE Healthcare Life Sciences) twice. A total of $10 \mu \mathrm{g} / \mathrm{ml}$ fluorescein isothiocyanate-Ulex Europaeus Agglutinin-I (Sigma-Aldrich; Merck KGaA) was added and the mixture was incubated at $37^{\circ} \mathrm{C}$ for $1 \mathrm{~h}$. Cells were observed under a fluorescence microscope (magnification, x40; CKX53; Olympus Corporation, Tokyo, Japan) and cells with positive dual-staining were considered to be differentiated EPCs.

The number of clones was determined under a microscope and the number of EPCs was calculated using the following formula: EPC concentration=number of colonies/original collected blood volume.

Detecting the changes in EPC number in the peripheral blood of patients with cancer prior to and following the administration of anti-angiogenic agents. A total of 20 patients with solid tumors (10 cases of liver cancer, 6 cases of osteosarcoma and 4 cases of stomach cancer) were selected according to the standards for clinical treatment with anti-angiogenic agents. 
Patients were enrolled between March 2014 and February 2015 and were aged 25 to 59 years old, with a male: female ratio of 3:2. Patients had no underlying conditions, history of surgery or allergies. The inclusion criteria were as follows: Clear diagnosis of solid tumors, no myocardial infarction and intracranial hemorrhage within a month, no organ infarction and deep venous thrombosis, no significant systemic infection, no chemotherapy radiotherapy history nearly a month and no other cancer treatment, including targeting medical treatment. The exclusion criteria were: Neutrophil count $<1.5 \times 10^{9} / 1$ or platelet count $<100 \times 10^{9} / 1$, women of childbearing age who serum pregnancy test was positive or long-term use of immunosuppressive agents after organ transplantation. The Ethics Committee of Gongli Hospital approved the study protocol, and written informed consent was obtained from all participating subjects. A total of $20 \mathrm{ml}$ blood was harvested prior to and following treatment and the testing method was the same as described above.

The absolute number of cells in the test sample (ND) was calculated using the following formula: Absolute number of cells=target cell number/number of cell microspheres $\mathrm{x}$ added number of cell microspheres. The method for the in vitro clonogenic counting assay was the same as described above.

Statistical analysis. Data were analyzed using Statistical Package for the Social Sciences (SPSS) software (version 13.0; SPSS Inc., Chicago, IL, USA). One-way analysis of variance with Dunnet's post test was used for statistical evaluation of significant differences among the groups. $\mathrm{P}<0.05$ was considered to indicate a statistically significant difference.

\section{Results}

Preparation and identification of artificial cell fluorescent microspheres. The cell fluorescent microspheres exhibited strong homogeneous fluorescence (Fig. 1; Q2) and the average fluorescence intensity was strong. Thus, CFSE-labeled cell beads were easily distinguished from non-labeled THP-1 cells (Fig. 1; Q1) and with maintained fluorescence, indicating that the obtained cell microspheres were feasible for the intended application.

Detection of EPCs in peripheral blood using single-platform flow cytometry. Regression curves for EPC number changed according to the reduction in the original blood sample volume (Fig. 2), indicating that this method was able to determine the number of EPCs in peripheral blood.

Detection of EPCs in peripheral blood using an in vitro clonogenic counting assay. Regression curves for EPC number altered according to the reduction in the original blood sample volume (Fig. 3), indicating that this method was able to determine the number of EPCs in peripheral blood. When comparing Figs. 2 and 3, there is a clear consistency between these two detection methods, indicating that single-platform flow cytometry may be used to feasibly and accurately determine the number of EPCs in peripheral blood.

EPCs in the peripheral blood of patients with cancer were counted prior to and following anti-angiogenic agent administration, using single-platform flow cytometry and the in vitro

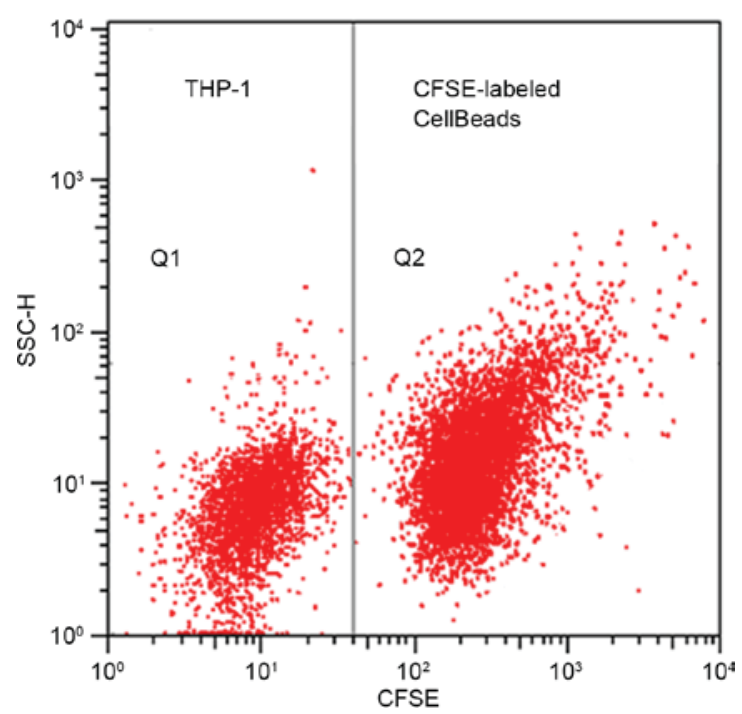

Figure 1. Number of EPCs detected using THP-1 human acute leukemia cells by single-platform flow cytometry. EPCs, endothelial progenitor cells; CSFE, 5-(and 6)-carboxyfluorescein diacetate succinimidyl ester; Q1, content of target cells; Q2, content of CFSE-labeled fluorescent microspheres.

clonogenic counting assay. Changes in the EPC number in the peripheral blood of patients with cancer prior to and following the administration of anti-angiogenic agents were measured using single-platform flow cytometry (Fig. 4A). Following anti-angiogenic agent administration, the EPC number was reduced when compared with the number prior to anti-angiogenic agent administration and in 12 patients this was statistically significant $(\mathrm{P}<0.05$; Fig. 4A). In addition, the results using the in vitro clonogenic counting assay were consistent with the flow cytometry results and 10 patients exhibited a significantly decreased EPC number following anti-angiogenic agent administration $(\mathrm{P}<0.05$; Fig. 4B). Overall, the data indicated that the anti-angiogenic treatment was able to significantly reduce the number of EPCs in peripheral blood $(\mathrm{P}<0.01$; Fig. $4 \mathrm{C})$.

\section{Discussion}

Current methods for determining EPC number may be divided into two categories. The first uses in vitro culture, in which cell differentiation is induced and cell clones that are formed are characterized as endothelial cells and counted. The second uses targeting to detect EPC-specific surface markers and this category may be divided into flow cytometry $(16,17,22,23)$ and gene expression-based polymerase chain reaction (PCR) quantitative detection $(24,25)$.

Although these two categories of detection methods have a large number of applications, they are essentially basic research methods and are difficult to apply to routine clinical testing, predominantly due to the following: Clone counting, although currently recognized as the most widely used EPC detection method, has the disadvantages of requiring time-consuming cell culturing, highly technical methods and is considered expensive; and flow cytometry, although it directly targets the indicators, is time consuming and requires expensive commercial fluorescent microspheres for quantitative analysis $(26,27)$. In addition, the physical properties of 
A

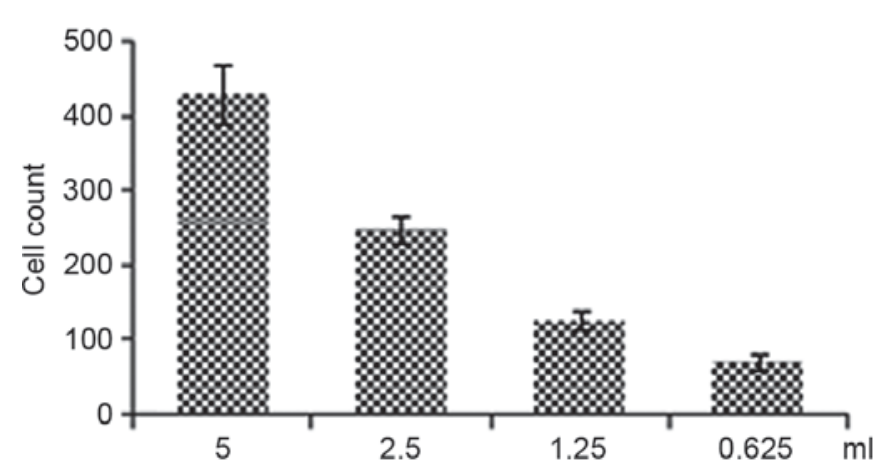

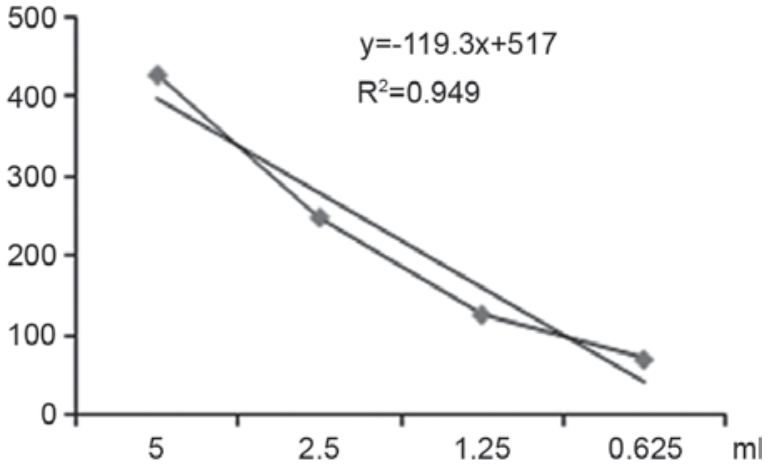

Figure 2. Detection of EPCs in 5, 2.5, 1.25 or $0.625 \mathrm{ml}$ of peripheral blood from patients with cancer by single-platform flow cytometry. (A) Contents of EPCs in different original-volume blood samples. (B) Regression equation of EPCs content in different original-volume blood samples. EPCs, endothelial progenitor cells.

A

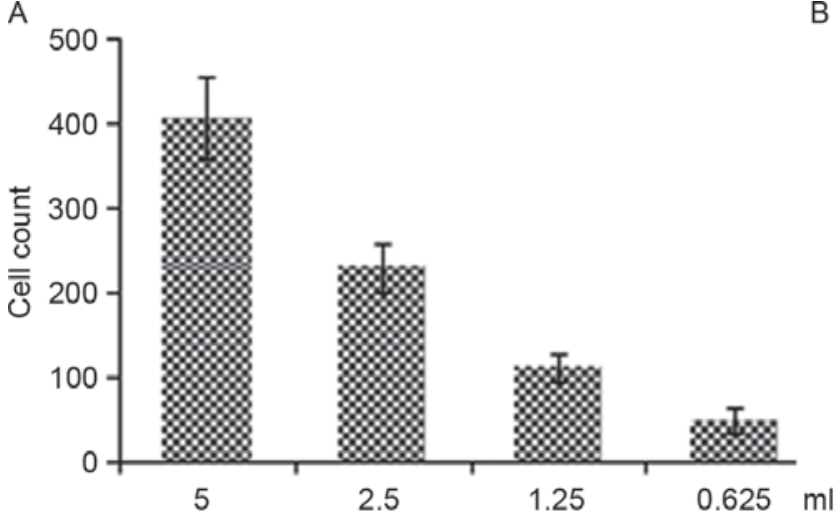

B

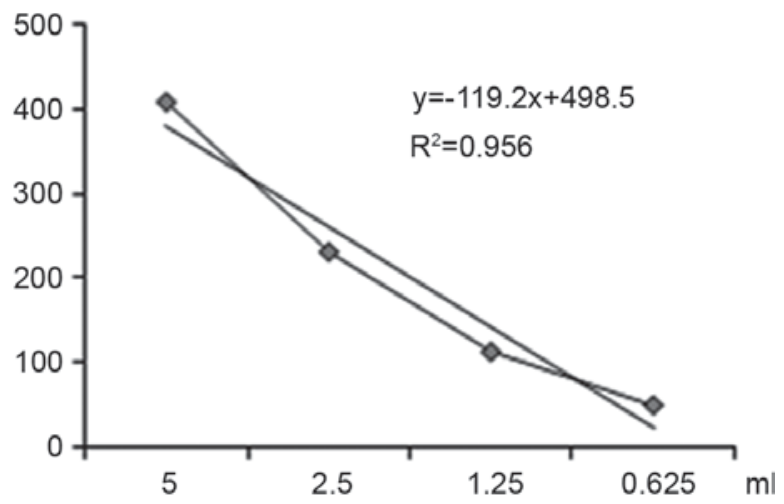

Figure 3. Detection of EPCs in 5, 2.5, 1.25 or $0.625 \mathrm{ml}$ of peripheral blood from patients with cancer by in vitro clonogenic counting assay. (A) Detection of EPCs in peripheral blood by in vitro clonogenic counting assay. (B) Regression equation of EPCs contents in different original-volume blood samples. EPCs, endothelial progenitor cells.

these commercial microspheres are different from those of the cells, thus leading to unreliable results and the operators are required to constantly adjust to novel detection processes. Furthermore, the PCR-based method, which detects specific indicators, has poor specificity among its shortcomings (28). The present study used single-platform flow cytometry with microspheres prepared according to the method recently reported in Cytometry A, regarding the use of the fluorescent dye, CFSE, to uniformly label leukemia cells and impart them with fluorescence (21). A known number of fluorescent cells were added to the test specimens as an internal reference for detection by single-platform flow cytometry, allowing the determination of the number of other, undetected cells in the specimens. In our previous study, CFSE-labeled cells were used to replace commercial fluorescent microspheres (21). In addition, they may be clearly distinguished from cells not labeled with fluorescence and have the same density and uniform sedimentation rate as the test cells; thus, they may be used as an internal reference for quantitative analysis and the results will be reliable (21). Therefore, once EPCs were immunolabeled, the newly constructed cell fluorescent microspheres were added, resulting in a quantitative detection, with improved accuracy, of EPCs in human peripheral blood, with reduced testing costs (1/5-1/6 of the current commercial microspheres). However, further studies are required to determine whether there are alternative cells or indicators, such as blood cells and dyes, that are more suitable than leukemia cells and CFSE for cell fluorescent microspheres, respectively.

In the present study, specific CD34, VEGFR-2 and CD133 antibodies were used to label EPC cells; however, no specific cell surface marker has been identified that is able to completely distinguish EPCs from hematopoietic cells. Previous results have indicated that mesenchymal stem cell-associated CD34//VE-cadherin $/ \mathrm{AC}^{-} 3^{+} / \mathrm{Flk}^{-1^{+}}$multipotent adult progenitor cells (MAPCs) may be converted to CD34 $/ \mathrm{VE}$-cadherin $/ \mathrm{AC} 133 \% \mathrm{Flk}^{+}$angioblasts by the action of VEGF and that these cells may be further differentiated into mature endothelial cells $(23,29,30)$ and become involved in tumor angiogenesis and wound healing. The cell surface markers of EPCs have not been fully elucidated and there continues to be large variances in the reported quantities of EPCs present in the circulation and uncertainty regarding the best enrichment and isolation methods $(31,32)$. Thus, the specific phenotype that may distinguish EPCs from hematopoietic cells or mature endothelial cells still requires further exploration, which provides the motivation for continued progression in the method described in the present study.

The number of EPCs is closely related to tumors due to the fact that tumor growth requires angiogenesis (33). Once 

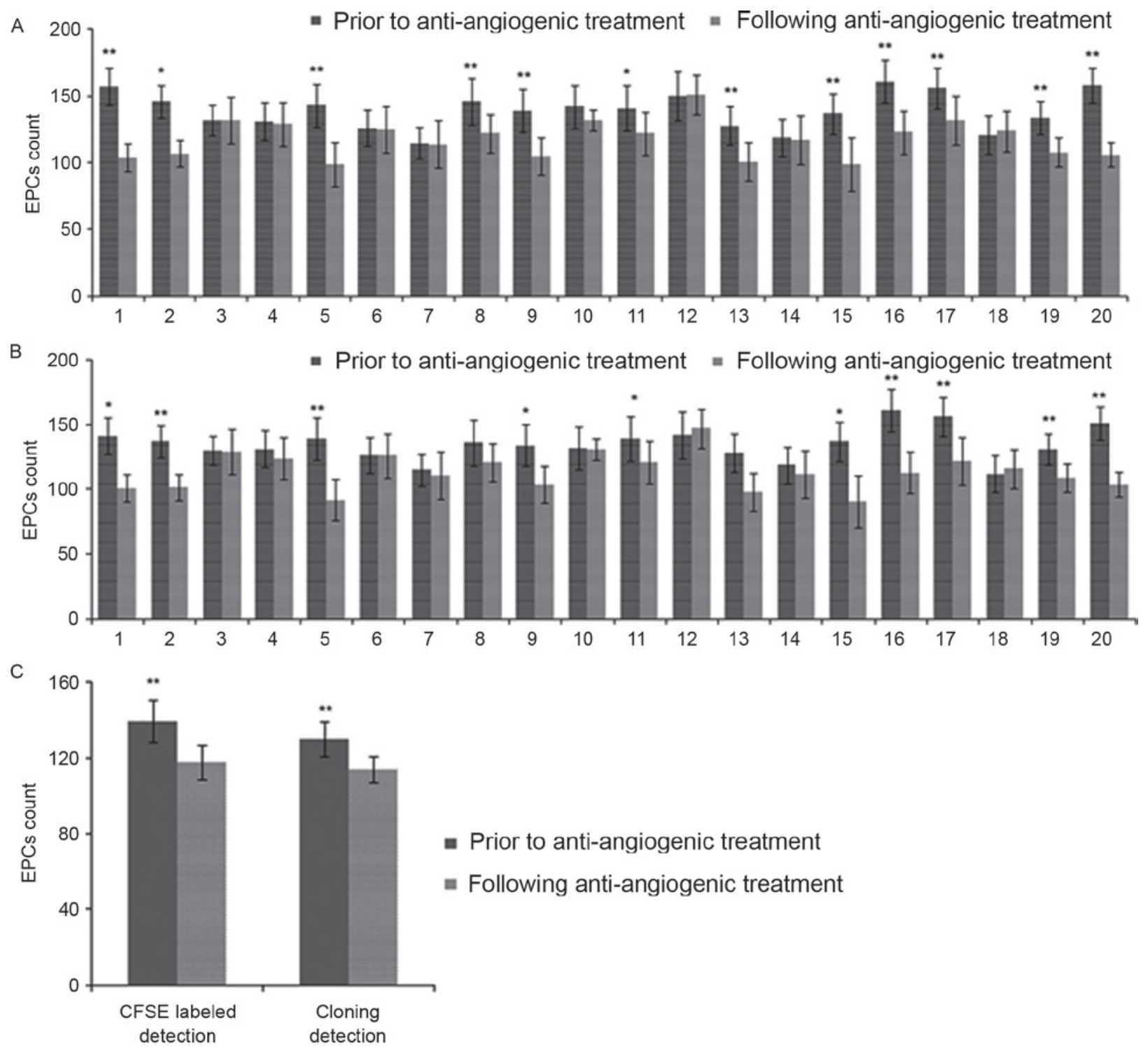

Figure 4. Changes of EPCs in peripheral blood of 20 patients with cancer prior to and following the administration of anti-angiogenic agents by (A) single-platform flow cytometry or (B) in vitro clonogenic counting assay. (C) Impact of anti-angiogenic agents on the number of EPCs. ${ }^{*} \mathrm{P}<0.05$ and ${ }^{* *} \mathrm{P}<0.01$ vs. following anti-angiogenic treatment. EPCs, endothelial progenitor cells; CSFE, 5-(and 6)-carboxyfluorescein diacetate succinimidyl ester.

a tumor reaches a size of $3 \mathrm{~mm}$, the tumor cannot survive unless novel blood vessels are produced $(5,6)$. Tumors are able to secrete specific factors that stimulate the bone marrow to increase EPC generation and to mobilize the generated EPCs into the peripheral blood, thus enriching local tumors with EPCs that participate in the formation of novel blood vessels $(4,25,34)$. Therefore, EPCs are an important indicator of tumor growth and prognosis and determining the number of EPCs has important clinical significance for patients with cancer. The present study determined the content of EPCs in the peripheral blood of patients with cancer. Compared with the results of an in vitro clonogenic counting assay, the accuracy of our method was reasonable.

Small arterial lesions may cause long-term high blood pressure, leading to tissue ischemia of important target organs such as the heart, brain and other organs (3). Endothelial dysfunction is caused by the destruction of the dynamic balance between endothelial injury and repair, and hypertension and endothelial dysfunction enhance one another. A previous study found that
EPC was able to differentiate into mature endothelial cells to repair damaged endothelial cells (35). Therefore, monitoring the number of EPCs may have important clinical significance for cardiovascular and cerebrovascular diseases. Therefore, monitoring the number of EPCs may have important clinical significance for cardiovascular and cerebrovascular diseases. The present study demonstrated that single-platform flow cytometry based on CFSE-labeled cell microspheres has unique advantages in determining the number of EPCs, overcomes the shortcomings of other methods and was objective and accurate. This method may be widely used in clinical practice for fast and accurate analysis of EPCs in peripheral blood.

\section{Acknowledgements}

The present study was funded by the Natural Science Foundation of Shanghai Science and Technology Committee (grant no. 11ZR1433000), the Foundation of Key Disciplines in 
Health Systems of Pudong New Dist. (grant no. PWZx2014-03) and the Foundation of Discipline Leader in Health Systems of Pudong New District (grant no. PWRd2014-02).

\section{References}

1. Hida K, Maishi N, Torii C and Hida Y: Tumor angiogenesis-characteristics of tumor endothelial cells. Int J Clin Oncol 21: 206-212, 2016.

2. Lopes-Bastos BM, Jiang WG and Cai J: Tumour-endothelial cell communications: Important and indispensable mediators of tumour angiogenesis. Anticancer Res 36: 1119-1126, 2016.

3. Giuliano $\mathrm{S}$ and Pagès G: Mechanisms of resistance to anti-angiogenesis therapies. Biochimie 95: 1110-1119, 2013.

4. Silván U, Diez-Torre A, Bonilla Z, Moreno P, Díaz-Núñez M and Aréchaga J: Vasculogenesis and angiogenesis in nonseminomatous testicular germ cell tumors. Urol Oncol 33: 268.e17-e28, 2015.

5. Vacca A and Ribatti D: Angiogenesis and vasculogenesis in multiple myeloma: Role of inflammatory cells. Recent Results Cancer Res 183: 87-95, 2011.

6. Tang HS, Feng YJ and Yao LQ: Angiogenesis, vasculogenesis, and vasculogenic mimicry in ovarian cancer. Int J Gynecol Cancer 19: 605-610, 2009.

7. Shchors K and Evan G: Tumor angiogenesis: Cause or consequence of cancer? Cancer Res 67: 7059-7061, 2007.

8. Duda DG, Cohen KS, Scadden DT and Jain RK: A protocol for phenotypic detection and enumeration of circulating endothelial cells and circulating progenitor cells in human blood. Nat Protoc 2: 805-810, 2007.

9. Ge YZ, Wu R, Lu TZ, Xin H, Yu P, Zhao Y, Liu H, Xu Z, Xu LW, Shen JW, et al: Circulating endothelial progenitor cell: A promising biomarker in clinical oncology. Med Oncol 32: 332, 2015.

10. de la Puente P, Muz B, Azab F and Azab AK: Cell trafficking of endothelial progenitor cells in tumor progression. Clin Cancer Res 19: 3360-3368, 2013.

11. Fuereder T, Wacheck V, Strommer S, Horak P, Gerschpacher M, Lamm W, Kivaranovic D and Krainer M: Circulating endothelial progenitor cells in castration resistant prostate cancer: A randomized, controlled, biomarker study. PLoS One 9: e95310, 2014.

12. Lau CK, Yang ZF, Ho DW, Ng MN, Yeoh GC, Poon RT and Fan ST: An Akt/hypoxia-inducible factor-1alpha/platelet-derived growth factor-BB autocrine loop mediates hypoxia-induced chemoresistance in liver cancer cells and tumorigenic hepatic progenitor cells. Clin Cancer Res 15: 3462-3471, 2009.

13. Ling CC, Ng KT, Shao Y, Geng W, Xiao JW, Liu H, Li CX, Liu XB, Ma YY, Yeung WH, et al: Post-transplant endothelial progenitor cell mobilization via CXCL10/CXCR3 signaling promotes liver tumor growth. J Hepatol 60: 103-109, 2014.

14. Igreja C, Fragoso R, Caiado F, Clode N, Henriques A, Camargo L, Reis EM and Dias S: Detailed molecular characterization of cord blood-derived endothelial progenitors. Exp Hematol 36: 193-203, 2008.

15. Ho JW, Pang RW, Lau C, Sun CK, Yu WC, Fan ST and Poon RT: Significance of circulating endothelial progenitor cells in hepatocellular carcinoma. Hepatology 44: 836-843, 2006.

16. Ishida Y, Kimura A, Nosaka M, Kuninaka Y, Shimada E, Yamamoto H, Nishiyama K, Inaka S, Takayasu T, Eisenmenger W and Kondo T: Detection of endothelial progenitor cells in human skin wounds and its application for wound age determination. Int J Legal Med 129: 1049-1054, 2015.

17. Lanuti P, Rotta G, Almici C, Avvisati G, Budillon A, Doretto P, Malara N, Marini M, Neva A, Simeone P, et al: Endothelial progenitor cells, defined by the simultaneous surface expression of VEGFR2 and CD133, are not detectable in healthy peripheral and cord blood. Cytometry A 89: 259-270, 2016.

18. Brunck ME, Andersen SB, Timmins NE, Osborne GW and Nielsen LK: Absolute counting of neutrophils in whole blood using flow cytometry. Cytometry A 85: 1057-1064, 2014.

19. Ngoma A, Saito S, Ohto H, Ikeda K, Yasuda H, Kawabata K, Kanno T, Kikuta A, Mochizuki K and Nollet KE: CD34 ${ }^{+}$cell enumeration by flow cytometry: A comparison of systems and methodologies. Arch Pathol Lab Med 135: 909-914, 2011.
20. Kleine TO, Nebe CT, Löwer C, Lehmitz R, Kruse R, Geilenkeuser WJ and Dorn-Beineke A: Modifications of haematology analyzers to improve cell counting and leukocyte differentiating in cerebrospinal fluid controls of the joint German society for clinical chemistry and laboratory medicine. Cytometry A 75: 688-691, 2009.

21. Cao FF, Xu LM, Peng B, Xie QH, Uzan G and Zhang DH: A routinely applicable way for using FCM in cell enumeration with CFSE-labeled CellBeads as internal standard. Cytometry A 75: 975-978, 2009.

22. Morita R, Sato K, Nakano M, Miura H, Odaka H, Nobori K, Kosaka T, Sano M, Watanabe H, Shioya T and Ito H: Endothelial progenitor cells are associated with response to chemotherapy in human non-small-cell lung cancer. J Cancer Res Clin Oncol 137: 1849-1857, 2011

23. Mund JA, Ingram DA, Yoder MC and Case J: Endothelial progenitor cells and cardiovascular cell-based therapies. Cytotherapy 11: 103-113, 2009.

24. Mehra N, Penning M, Maas J, Beerepoot LV, van Daal N, van Gils CH, Giles RH and Voest EE: Progenitor marker CD133 mRNA is elevated in peripheral blood of cancer patients with bone metastases. Clin Cancer Res 12: 4859-4866, 2006.

25. Steurer M, Kern J, Zitt M, Amberger A, Bauer M, Gastl G, Untergasser $\mathrm{G}$ and Gunsilius E: Quantification of circulating endothelial and progenitor cells: Comparison of quantitative PCR and four-channel flow cytometry. BMC Res Notes 1: 71, 2008.

26. Harrison GM, Bennett AJ, Moody M, Read GF and Williams PE: Use of formalin-fixed, propidium iodide-stained human leukocytes as a standard for enumerating $\mathrm{CD} 4^{+} \mathrm{T}$ lymphocytes in a single-platform assay. Clin Diagn Lab Immunol 8: 397-401, 2001.

27. Houston JP, Naivar MA and Freyer JP: Digital analysis and sorting of fluorescence lifetime by flow cytometry. Cytometry A 77: 861-872, 2010.

28. Churro C,Pereira P, Vasconcelos V and ValérioE: Species-specific real-time PCR cell number quantification of the bloom-forming cyanobacterium Planktothrix agardhii. Arch Microbiol 194: 749-757, 2012.

29. Pradhan KR, Mund JA, Claussen HL, Gosiengfiao YC, Radulescu VC, Ballard JJ, Liu Z, Vik TA and Case J: A pilot study of circulating endothelial and hematopoietic progenitor cells in children with sarcomas. J Pediatr Hematol Oncol 37: 443-448, 2015

30. Rusak M, Radzikowska U, Glowinska-Olszewska B, Dobrenko E, Piotrowska-Jastrzebska J, Dabrowska M, Bodzenta-Lukaszyk A, Bossowski A and Moniuszko M: Endothelial progenitor cell levels in juvenile idiopathic arthritis patients: Effects of anti-inflammatory therapies. Pediatr Rheumatol Online J 13: 6 , 2015.

31. Tagawa S, Nakanishi C, Mori M, Yoshimuta T, Yoshida S, Shimojima M, Yokawa J, Kawashiri MA, Yamagishi M and Hayashi K: Determination of early and late endothelial progenitor cells in peripheral circulation and their clinical association with coronary artery disease. Int J Vasc Med 2015: 674213, 2015.

32. Fox A, Smythe J, Fisher N, Tyler MP, McGrouther DA, Watt SM and Harris AL: Mobilization of endothelial progenitor cells into the circulation in burned patients. Br J Surg 95: 244-251, 2008.

33. Li Calzi S, Neu MB, Shaw LC, Kielczewski JL, Moldovan NI and Grant MB: EPCs and pathological angiogenesis: When good cells go bad. Microvasc Res 79: 207-216, 2010.

34. Takahashi T, Kalka C, Masuda H, Chen D, Silver M, Kearney M, Magner M, Isner JM and Asahara T: Ischemia- and cytokine-induced mobilization of bone marrow-derived endothelial progenitor cells for neovascularization. Nat Med 5: 434-438, 1999.

35. Ekholm L, Kahlenberg JM, Barbasso Helmers S, Tjärnlund A, Yalavarthi S, Zhao W, Seto N, Betteridge Z, Lundberg IE and Kaplan MJ: Dysfunction of endothelial progenitor cells is associated with the type I IFN pathway in patients with polymyositis and dermatomyositis. Rheumatology (Oxford) 55: 1987-1992, 2016. 